\title{
Central nervous system penetration and enhancement of temozolomide activity in childhood medulloblastoma models by poly(ADP-ribose) polymerase inhibitor AG-014699
}

\author{
RA Daniel', AL Rozanska', EA Mulligan', Y Drew', HD Thomas', DJ Castelbuono', Z Hostomsky', \\ ER Plummer', DA Tweddle', AV Boddy', SC Clifford ${ }^{*, 1}$ and NJ Curtin*,I \\ 'Northern Institute for Cancer Research, Newcastle University, Paul O'Gorman Building, Newcastle upon Tyne, NE2 4HH, UK; ${ }^{2}$ Pfizer Oncology Inc., \\ La Jolla, CA, USA
}

\begin{abstract}
BACKGROUND: Temozolomide shows activity against medulloblastoma, the most common malignant paediatric brain tumour. Poly(ADP-ribose) polymerase (PARP) inhibitors enhance temozolomide activity in extracranial adult and paediatric human malignancies.

METHODS: We assessed the effect of AG-014699, a clinically active PARP inhibitor, on temozolomide-induced growth inhibition in human medulloblastoma models. Pharmacokinetic, pharmacodynamic and toxicity assays were performed in tumour-bearing mice. RESULTS: Sensitivity to temozolomide in vitro was consistent with methylguanine methyltransferase (MGMT) and DNA mismatch repair (MMR) status; $\mathrm{MGMT}^{+} \mathrm{MMR}^{+} \mathrm{D} 384 \mathrm{Med}$ cells (temozolomide $\mathrm{Gl}_{50}=220 \mu \mathrm{M}$ ), representative of most primary medulloblastomas, were sensitised fourfold by AG-014699; $\mathrm{MGMT}^{-} \mathrm{MMR}^{+}$D425Med cells were hypersensitive $\left(\mathrm{GI}_{50}=9 \mu \mathrm{M}\right)$ and not sensitised by AG-0 14699, whereas MGMT ${ }^{+} \mathrm{MMR}^{-}$temozolomide-resistant D283Med cells $\left(\mathrm{Gl}_{50}=807 \mu \mathrm{M}\right)$ were sensitised 20-fold. In xenograft models, co-administration of AG-014699 produced an increase in temozolomide-induced tumour growth delay in D384Med xenografts. Consistent with the in vitro data, temozolomide caused complete tumour regressions of D425Med xenografts, whereas D283Med xenografts were relatively resistant. AG-014699 was not toxic, accumulated and reduced PARP activity $\geqslant 75 \%$ in xenograft and brain tissues.

CONCLUSION: We show for the first time central nervous system penetration and inhibition of brain PARP activity by AG-0 I4699. Taken together with our in vitro chemosensitisation and toxicity data, these findings support further evaluation of the clinical potential of AG-014699-temozolomide combinations in intra-cranial malignancies.

British Journal of Cancer (2010) 1 03, I588- 1596. doi:I0.1038/sj.bjc.6605946 www.bjcancer.com
\end{abstract}

Published online 26 October 2010

(C) 2010 Cancer Research UK

Keywords: medulloblastoma; PARP; CNS; temozolomide; xenograft

Medulloblastoma is the most common malignant paediatric brain tumour and accounts for almost $10 \%$ of all childhood cancer deaths. The clinical outcome for patients with medulloblastoma is variable and overall $\sim 40 \%$ of children with medulloblastoma will die of their disease (Pizer and Clifford, 2008, 2009). Current therapies for medulloblastoma comprise maximal surgical resection, craniospinal irradiation and chemotherapy. The use of these combined modalities has led to long-term survival rates of $\sim 80 \%$ in standard risk cases and $\sim 40-60 \%$ in high-risk cases (infants $<3$ years or metastatic disease at presentation). However, the development of relapsed, drug-resistant disease is common, particularly in high-risk cases $(\sim 50 \%)$ and long-term side effects associated with these therapies, including intellectual and neuroendocrine impairment associated with craniospinal irradiation

* Correspondence: Professor NJ Curtin or Professor SC Clifford; E-mail: n.j.curtin@ncl.ac.uk or s.c.clifford@ncl.ac.uk

Received 17 August 2010; revised 10 September 2010; accepted 18 September 2010; published online 26 October 2010 (reviewed in Pizer and Clifford, 2009). New therapeutic approaches, particularly those that may result in improved therapeutic outcome and reduced long-term sequelae, are clearly warranted.

Temozolomide shows significant single-agent activity in adult oligodendrogliomas and high-grade astrocytomas and evidence of activity in pre-clinical medulloblastoma models (Friedman et al, 1995; Middlemas et al, 2000; Macdonald, 2001; van den Brent et al, 2003). Recently, Phase I and II trials of temozolomide, using a variety of schedules, have been undertaken in paediatric brain tumour patients, including medulloblastoma (reviewed in Barone et al, 2006). The maximum-tolerated dose and dose-limiting toxicities in paediatric patients appear to be similar to those in adults, and encouraging responses have been observed against medulloblastoma (Baruchel et al, 2006; Nicholson et al, 2007; Wang et al, 2009), supporting further investigation of temozolomide in this disease.

DNA damage signalling and repair pathways are novel and promising targets for improved cancer therapy, particularly with regard to radio- and chemosensitisation. Genomic instability, which often results from DNA damage signalling and repair 
defects, is a common characteristic of cancer. Such defects can render the cancer cell more dependent on complementary signalling and repair pathways, which are often upregulated. These upregulated pathways can compromise the efficacy of DNAdamaging anticancer agents and represent a novel therapeutic target to specifically sensitise cancer cells (reviewed in Curtin, 2007). Resistance to temozolomide therapy has been associated with high levels of methylguanine methyltransferase (MGMT) and defects in mismatch repair (MMR) (Curtin et al, 2004). In adult glioma patients, sensitivity to temozolomide is associated with methylation of the MGMT promoter (Hegi et al, 2005). Attempts to modulate temozolomide resistance through inhibition of MGMT with co-administration of $\mathrm{O}^{6}$-benzylguanine have not lived up to their pre-clinical promise in adult brain tumour patients (reviewed in Curtin, 2007). This approach has also been tested in the Phase I setting in children, but the numbers are too small to determine if success is likely to be greater (Broniscer et al, 2007). In the pre-clinical setting, defects in DNA MMR are associated with resistance to temozolomide, which is not overcome by MGMT inhibition (Curtin et al, 2004; Cheng et al, 2005). In the Phase I $\mathrm{O}^{6}$-benzylguanine combination study, microsatellite instability, an indication of defective MMR, was observed in four of the six medulloblastoma patients. The MGMT status of primary medulloblastomas is controversial, with variable estimates in the literature, although in general MGMT defects appear relatively uncommon (reviewed in Lindsey et al, 2005). Similarly, in other studies, MMR defects occur only in a small subset of medulloblastomas (Viana-Pereira et al, 2009).

An alternative strategy to enhance temozolomide activity is to inhibit poly(ADP-ribose) polymerase-1 and -2 (PARP-1 and PARP-2). These enzymes are activated by DNA single- and doublestrand breaks and promote their repair through the relaxation of chromatin and recruitment of other repair proteins. We have previously shown that PARP inhibitors can restore temozolomide sensitivity to MMR-defective cells (Curtin et al, 2004), and sensitise tumour cells and xenografts, including models competent for MMR and MGMT, to temozolomide (Calabrese et al, 2004). The first PARP inhibitor to enter clinical trial for cancer therapy was AG-014699, in combination with temozolomide (Plummer et al, 2008), which was selected on the basis of pre-clinical data in models of adult human malignancies (Thomas et al, 2007). AG-014699 has favourable pharmacokinetics and causes profound and sustained inhibition of PARP activity in surrogate normal tissues (peripheral blood lymphocytes) and tumours (Plummer et al, 2008). In the Phase II setting, AG-014699 doubled the reported response rate to temozolomide (Plummer et al, 2006). We have recently been investigating the potential of AG-014699 in models of paediatric malignancies and found that it increased the efficacy of temozolomide and topotecan in neuroblastoma cells and xenografts (Daniel et al, 2009).

We wished to investigate if AG-014699 could be beneficial for the treatment of intra-cranial tumours, using medulloblastoma as a model. Central nervous system (CNS) tumours can be more difficult to treat because of the blood-brain barrier (BBB) that limits drug uptake into CNS tissues. The BBB is a physical and biochemical impediment to the transport of drugs into the CNS by virtue of highly impenetrable vascular endothelial cells and an abundance of drug efflux pumps (reviewed in Deeken and Loscher, 2007). In general, for good CNS penetration, drugs should have few hydrogen bond donors and positive charges, lower polar surfaces, reduced flexibility and be $\angle 400 \mathrm{Da}$ in size (Deeken and Loscher, 2007). AG-014699 is the phosphate salt of the active compound AG-014447, which has a molecular weight of $323 \mathrm{Da}, \mathrm{p} K_{\mathrm{a}}$ of 9.6 and a $c \log D$ of 0.7 (Thomas et al, 2007). It is likely to exist as a protonated amine at physiological $\mathrm{pH}$ and has some polar functionalities that may not favour CNS penetration. The BBB has been hypothesised to be less intact in primary and metastatic brain tumours, at least in the case of large tumours, in which the physiology of the endothelial cells is different from the rest of the brain (reviewed in Daniel et al, 2009). However, a number of other PARP inhibitors, including ones with similar structure to AG-014447, have been shown to penetrate and have biological activity in the brain in pre-clinical models of adult malignancies (Tentori et al, 2003; Hattori et al, 2004; Donawho et al, 2007). Recent clinical trials of the PARP inhibitor, olaparib, showed evidence of regression in a brain metastasis in one patient (Fong et al, 2009). Temozolomide shows good CNS penetration, and uptake into human gliomas was higher than the surrounding normal brain, owing to breakdown of the $\mathrm{BBB}$ and possibly tumour-induced angiogenesis (Rosso et al, 2009). Furthermore, radiotherapy can also disrupt the BBB (reviewed in Deeken and Loscher, 2007). However, it may be hypothesised that, for smaller tumours including the CNS metastatic deposits commonly associated with medulloblastoma relapse, the BBB may still be intact. It is therefore important to determine if AG-014699 can penetrate CNS tissues.

We report here the pre-clinical assessment of AG-014699, in vitro and in vivo in human medulloblastoma models. Our data show the distribution of AG-014699 and inhibition of PARP in CNS tissue for the first time and show the clear potential of PARP inhibitors in combination with temozolomide for the improved therapy of medulloblastoma.

\section{MATERIALS AND METHODS}

\section{Materials}

Temozolomide was a gift from Cancer Research UK (London, UK), and AG-014699 ( $\mathrm{PO}_{4}$ salt of AG-014447, now also called PF-01367338) was a gift from Pfizer Oncology (La Jolla, CA, USA). Temozolomide was dissolved in dimethyl sulphoxide (DMSO) before addition to cell cultures at a final concentration of $0.5 \%\left(\mathrm{vv}^{-1}\right)$ DMSO. For in vivo evaluation, temozolomide was dissolved in saline immediately before administration. $10 \mathrm{H}$ mouse monoclonal antibody to ADP-ribose polymers was a kind gift from Dr Alexander Burkle (University of Konstanz, Konstanz, Germany). Other chemicals and reagents were obtained from Sigma (Poole, UK), unless otherwise stated.

\section{Cell lines and culture}

Three medulloblastoma cell lines were selected for study. D384Med and D425Med were kind gifts from Dr D Bigner (Duke University, Durham, NC, USA). D283Med was obtained from the American Type Culture Collection (Manassas, VA, USA). Published cell line karyotypes and genetic features were confirmed in each cell line before use; all three lines harboured genetic lesions consistent with primary medulloblastomas (Langdon et al, 2006). All three medulloblastoma cell lines were maintained using standard methods, in Dulbecco's modified Eagle's medium containing $20 \%$ fetal calf serum (Life Technologies, Paisley, UK), and were confirmed to be mycoplasma free.

\section{Cell line protein expression}

Protein lysates were prepared from each cell line using standard methods and examined for the presence of the PARP-1 protein (H-250 anti-PARP-1 antibody; Santa Cruz Biotechnology, Heidelberg, Germany) and $\alpha$-tubulin control using western blot analysis $(50 \mu \mathrm{g}$ protein loaded per well). Lysates were also blotted for cell line expression of MGMT and the MMR proteins MLH1, MSH2, MSH3, MSH6 and PMS2 (all mouse monoclonal antibodies; BD Biosciences Pharmingen, Oxford, UK). 


\section{Inhibition of cellular PARP activity by AG-014699}

Inhibition of PARP activity in 5000 exponentially growing D283Med cells was measured following treatment with a range of AG-014699 concentrations $(0-1 \mu \mathrm{M})$, in comparison with DMSOonly controls. Maximally stimulated PARP activity was measured in replicate samples $(n \geqslant 3)$ of permeabilised cells by immunological detection of the amount of poly(ADP-ribose) (PAR) formed, using $10 \mathrm{H}$ anti-PAR antibody, during a 6-min incubation with $\mathrm{NAD}^{+}$and oligonucleotide (substrate and activator) by reference to a PAR (Biomol Research Labs, Plymouth, PA, USA) standard curve using a GCLP-validated assay described previously (Plummer et al, 2005).

\section{In vitro growth inhibition and cytotoxicity assays}

Cell growth inhibition was estimated in exponentially growing D425Med, D283Med and D384Med cells in 96-well plates. Seeding densities of $1 \times 10^{3}, 3 \times 10^{3}$ and $3 \times 10^{3}$ cells, respectively, ensured exponential growth for the duration of the experiment. At $24 \mathrm{~h}$ (D384Med) or $48 \mathrm{~h}$ (D283Med and D425Med) after seeding, cells were exposed to varying concentrations of temozolomide, as described in the Results, in the presence or absence of $0.4 \mu \mathrm{M}$ AG-014699, a concentration previously shown to enhance temozolomide cytotoxicity in adult tumour cell lines (Thomas et al, 2007). After 3 days (D425Med and D384Med) or 5 days (D283Med) of culture (equivalent to approximately three cell divisions), the cell viability was quantified using an XTT cell proliferation kit assay (Roche, Mannheim, Germany), according to the manufacturer's instructions. Cell growth was expressed as a percentage in relation to DMSO or $0.4 \mu \mathrm{M}$ AG-014699-alone controls. The concentration of temozolomide, alone or in combination with AG-014699, that inhibited growth by $50 \%\left(\mathrm{GI}_{50}\right)$ was calculated from computer-generated curves (GraphPad Software, San Diego, $\mathrm{CA}$, USA). The potentiation factor ${ }_{50}\left(\mathrm{PF}_{50}\right)$ is defined as the ratio of the $\mathrm{GI}_{50}$ of temozolomide in the presence of AG-014699 to the $\mathrm{GI}_{50}$ of temozolomide alone. All data were from at least three independent experiments.

\section{Establishment of D425Med, D283Med and D384Med tumour xenografts}

All of the in vivo experiments were reviewed and approved by the relevant institutional animal welfare committees, and performed according to national law. Female athymic nude mice (CD1 nu/nu; Charles River, Margate, UK) used for anti-tumour studies were maintained and handled in isolators under specific pathogen-free conditions. D425Med, D283Med and D384Med $\left(1 \times 10^{7}\right.$ exponentially growing cells per mouse, harvested and implanted in growth media) xenografts were established by sub-cutaneous implantation into CD-1 nude mice. Before use in experiments, xenograft establishment was defined as when two-dimensional calliper measurements of tumours reached approximately $5 \times 5 \mathrm{~mm}^{2}$. Treatment was initiated when sufficient number of mice had established tumours to allow randomisation into treatment groups: day 17 for D425Med, day 26 for D384Med and day 32 for D283Med. Tumour-bearing mice were killed 100 days after the start of treatment or when two dimensions of a tumour xenograft reached $10 \mathrm{~mm}$ or one dimension reached $15 \mathrm{~mm}$, whichever was the earliest.

\section{AG-014699 pharmacokinetics and pharmacodynamics in mouse plasma, brain and D283Med tumour xenografts}

One or four daily doses of PARP inhibitor AG-014699 $\left(1 \mathrm{mg} \mathrm{kg}^{-1}\right.$ intraperitoneally (i.p.)) were given to $\mathrm{CD}-1$ nude mice bearing established D283Med xenografts. At $0.5,2,6$ and $24 \mathrm{~h}$ after the initial or fourth daily dose of AG-014699, three animals per time point were bled by cardiac puncture under general anaesthesia, and then killed. Plasma was separated from the blood samples using standard methods and stored at $-80^{\circ} \mathrm{C}$. The brains and tumours were removed, snap frozen in liquid nitrogen and stored at $-80^{\circ} \mathrm{C}$ before analysis. Blood, tumour and brain tissue were removed from three untreated control animals and processed in the same way.

\section{AG-014699 distribution in plasma, brain and tumour xenograft samples}

AG-014699 is the phosphate salt of AG-014447 and rapidly liberates the parent drug following injection. The concentration of AG-014447 was determined in plasma and tissue homogenates $\left(1: 4\left(\mathrm{w} \mathrm{v}^{-1}\right)\right.$ in $\left.\mathrm{PBS}\right)$ of brain and tumour after protein precipitation with acetonitrile by liquid chromatography/mass spectrometry/mass spectrometry using a turbo ion spray interface and multiple reaction monitoring in the positive ion mode (API 4000; Applied Biosystems, Warrington, Cheshire, UK) and a deuterated internal standard as described previously (Plummer et al, 2008). The lower limit of quantitation was $1 \mathrm{ng} \mathrm{ml}^{-1}$. Plasma pharmacokinetics of AG-014447 were analysed using a noncompartmental approach in WinNonlin version 5.2.

\section{Pharmacodynamics in brain and tumour tissue: PARP-1 activity assays}

PARP activity was determined in homogenates of subcutaneous D283Med xenografts and brain tissue (see above). Maximally stimulated PARP activity was measured in replicate samples $(n \geqslant 3)$ of a $1: 1000$ dilution of the homogenate as described for permeabilised D283Med cells (see above). Data were calculated as pmol PAR per mg protein by reference to the PAR standard curve and protein content of the sample and expressed as a percentage of the corresponding tissue from the saline-treated control animals. The mean PARP activity in xenograft and brain samples taken at each time point was expressed as a percentage of the mean PARP activity of control xenografts from untreated mice $(n=3)$.

\section{Tumour growth inhibition in vivo}

CD-1 nude mice bearing palpable, established subcutaneous D425Med, D283Med and D384Med xenografts were treated with normal saline (control animals), temozolomide $\left(68 \mathrm{mg} \mathrm{kg}^{-1}\right.$ per os (p.o.)) or AG-014699 ( $1 \mathrm{mg} \mathrm{kg}^{-1}$ i.p.) alone or in combination, daily for 5 days (five mice per group). For drug combinations, AG-014699 was administered immediately after administering temozolomide. Tumour volumes, determined from twodimensional calliper measurements and the equation $a^{2} \times b / 2$ (where $a$ is the length and $b$ is the width of the tumour), were monitored for the experimental period (up to 100 days), and are presented for each group of mice as median relative tumour volume (RTV) values. Relative tumour volume 1 is the tumour volume on the initial day of treatment (day 0), and RTV4 is the tumour volume four times that on the initial day of treatment. Tumour growth delay (TGD) is defined as the time to RTV4 in drug-treated mice compared with the time to RTV4 in control (vehicle alone) mice. Median tumour volume is shown, rather than the mean, as this is generally accepted as the most statistically reliable representation of the average growth rate of tumours in a small group of mice, if a normal distribution of tumour volumes cannot be assumed. Tumour growth delay was calculated as: median time to RTV4 in treated group-median time to RTV4 in control group. Percentage enhancement was calculated as $100 \times($ TGD TMZ + AG-014699/TGD TMZ alone) -100 (Calabrese et al, 2004). 


\section{RESULTS}

\section{AG-014699 and PARP-1 inhibition in permeabilised medulloblastoma cells}

AG-014699 is a potent inhibitor of purified full-length human PARP-1 (Thomas et al, 2007). We assayed PARP-1 activity in permeabilised D283Med cells after AG-014699 treatment. AG-014699, at concentrations of $0.1,0.4$ and $1 \mu \mathrm{M}$, inhibited PARP-1 activity by $81.1,96.8$ and $97.1 \%$, respectively. All previous cellular chemosensitisation studies with this class of PARP inhibitor, including AG-014699 have used a concentration of $0.4 \mu \mathrm{m}$ (Calabrese et al, 2004; Thomas et al, 2007). As this concentration also caused almost total inhibition of the PARP activity in medulloblastoma cells, we used a concentration of $0.4 \mu \mathrm{M}$ AG-014699 to study the chemosensitisation of temozolomide, enabling comparison with previous data.

\section{Cell line expression of inhibition target and DNA repair pathway proteins}

All three cell lines selected for study expressed PARP-1 by western blotting (Figure 1). D384Med also clearly expressed MGMT and the

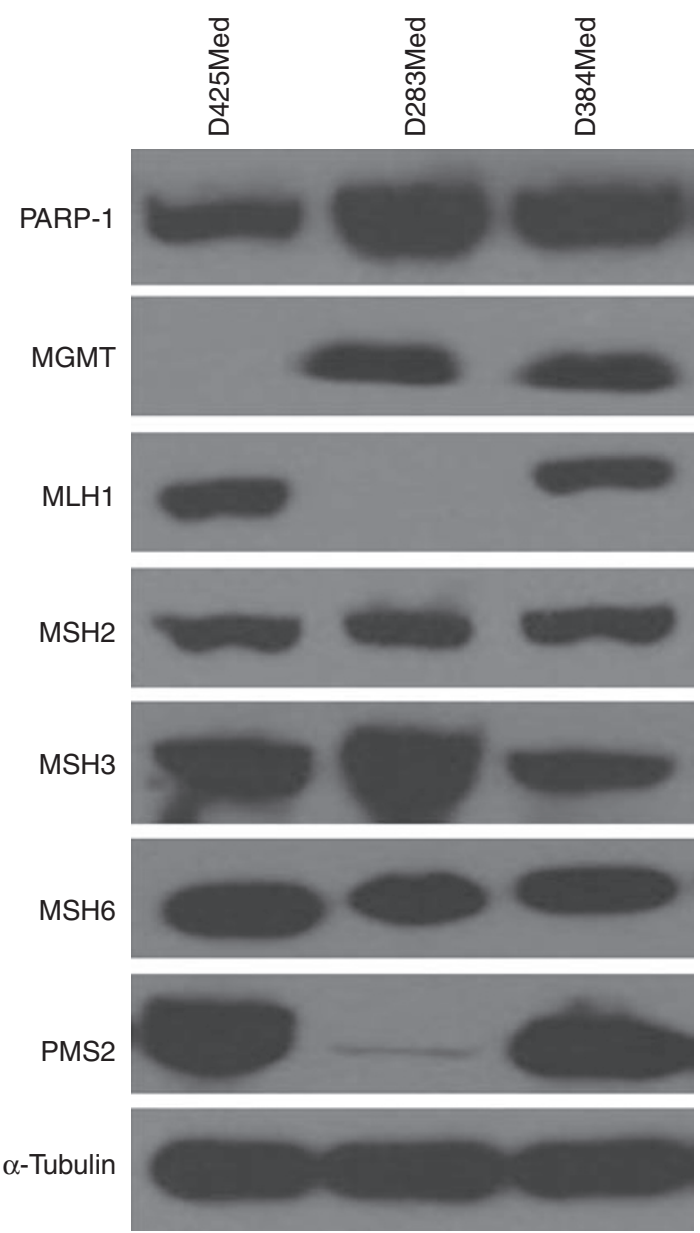

Figure I Protein expression levels of PARP-I and proteins related to temozolomide sensitivity/resistance in medulloblastoma cell lines. Expression levels of $\alpha$-tubulin (control) are also shown. Protein expression was determined for $50 \mu \mathrm{g}$ of whole-cell lysate by western blot analysis and visualised by chemoluminescence. D425 cells have no detectable MGMT and D283 cells have no detectable MLH-I and minimal PMS2 consistent with MGMT and mismatch repair deficiency, respectively, whereas D384 cells are proficient for both.
MMR proteins MLH1, MSH2, MSH3, MSH6 and PMS2, indicating competence in these pathways implicated in temozolomide sensitivity. However, two of the cell lines were found to be compromised in the expression of some of these proteins. D425Med lacked MGMT and D283Med was deficient in MLH1 and had barely detectable PMS2, indicating MMR dysfunction.

\section{Potentiation of temozolomide induced growth inhibition by AG-014699}

We measured the growth of cells exposed to increasing concentrations of temozolomide alone or in combination with $0.4 \mu \mathrm{M}$ AG-014699 continuously, over a period of three cell doublings. Representative growth inhibition curves of D425Med (Figure 2A), D283Med (Figure 2B) and D384Med (Figure 2C) are shown. Pooled $\mathrm{GI}_{50}$ data for temozolomide with and without AG-014699 from at least three independent experiments for each of the three cell lines are shown in Table 1. AG-014699 alone was not growth inhibitory at the concentration used $(0.4 \mu \mathrm{M})$ (data not shown). Temozolomide alone caused a concentration-dependent inhibition of growth in all three cell lines. Cell lines exhibited variable levels of sensitivity to temozolomide alone. The MGMTdeficient D425Med cells were hypersensitive to temozolomide, and the MMR-defective D283Med cells were nearly 100 times less sensitive, as expected. The D384Med cells, which were proficient in both pathways, displayed intermediate sensitivity. There was also considerable variation in the degree of chemosensitisation by AG- 014699 between the cells, with almost 20 -fold sensitisation of the MMR-defective, D283Med, cells compared with >3-fold sensitisation in the MMR- and MGMT-competent D384Med cells, but no sensitisation of the MGMT-deficient, D425Med, cells.

\section{AG-014699 levels in plasma, brain tissue and D283Med tumour xenografts}

A dose of $1 \mathrm{mg} \mathrm{kg}^{-1}$ AG-014699 daily five times has previously been shown to be non-toxic and sufficient for profound chemosensitisation of human colon and neuroblastoma cancer xenografts to temozolomide (Thomas et al, 2007; Daniel et al, 2009). Therefore, we selected this dose to investigate chemosensitisation of medulloblastoma xenografts. Before undertaking these studies, we determined the distribution of the PARP inhibitor in the plasma, and to brain and tumour tissue, following a single dose and four daily doses of $1 \mathrm{mg}$ AG-014699 per kg i.p. in mice bearing D283Med sub-cutaneous xenografts. We measured concentrations of AG-014447 at either $0.5,2,6$ or $24 \mathrm{~h}$ after dosing (three mice per time point).

After the first dose of AG-014699 (Figure 3Ai), a peak plasma concentration of $56 \pm 13 \mathrm{ng} \mathrm{ml}^{-1}(172 \pm 39 \mu \mathrm{M})$ AG-014447 was detected at the earliest time point after injection. Thereafter, the levels decreased rapidly, such that at $24 \mathrm{~h}$ they were below the level of quantitation.

Levels in the tumour were higher than that in the plasma at all time points (Figure 3A), for example, $230-1510 \mathrm{~nm}$ in the tumour compared with $131-209 \mathrm{~nm}$ in plasma at $30 \mathrm{~min}$. There was also significant and prolonged retention within the tumour, such that at $24 \mathrm{~h}$ after injection, levels of between 74 and $196 \mathrm{~nm}$ were still detectable. Surprisingly, given its physical and chemical properties, significant levels of AG-014447 were also detected in the brain tissue. Although these were initially lower than those in the plasma (20-40 $\mathrm{nm}$ at $30 \mathrm{~min}$ ), there was some degree of retention such that at $24 \mathrm{~h}$ the levels were up to 10 -fold higher than that in the plasma (1-30 nM in brain compared with 1.9-2.4 nM in plasma). After the fourth daily dose of AG-014699 (Figure 3Aii), peak plasma AG-014447 concentrations were similar to those following a single dose. Levels in the brain were only marginally greater than plasma levels at $6 \mathrm{~h}$. However, high concentrations (639-932 nM) were retained in the tumour for the entire period. In the plasma, AUCs 

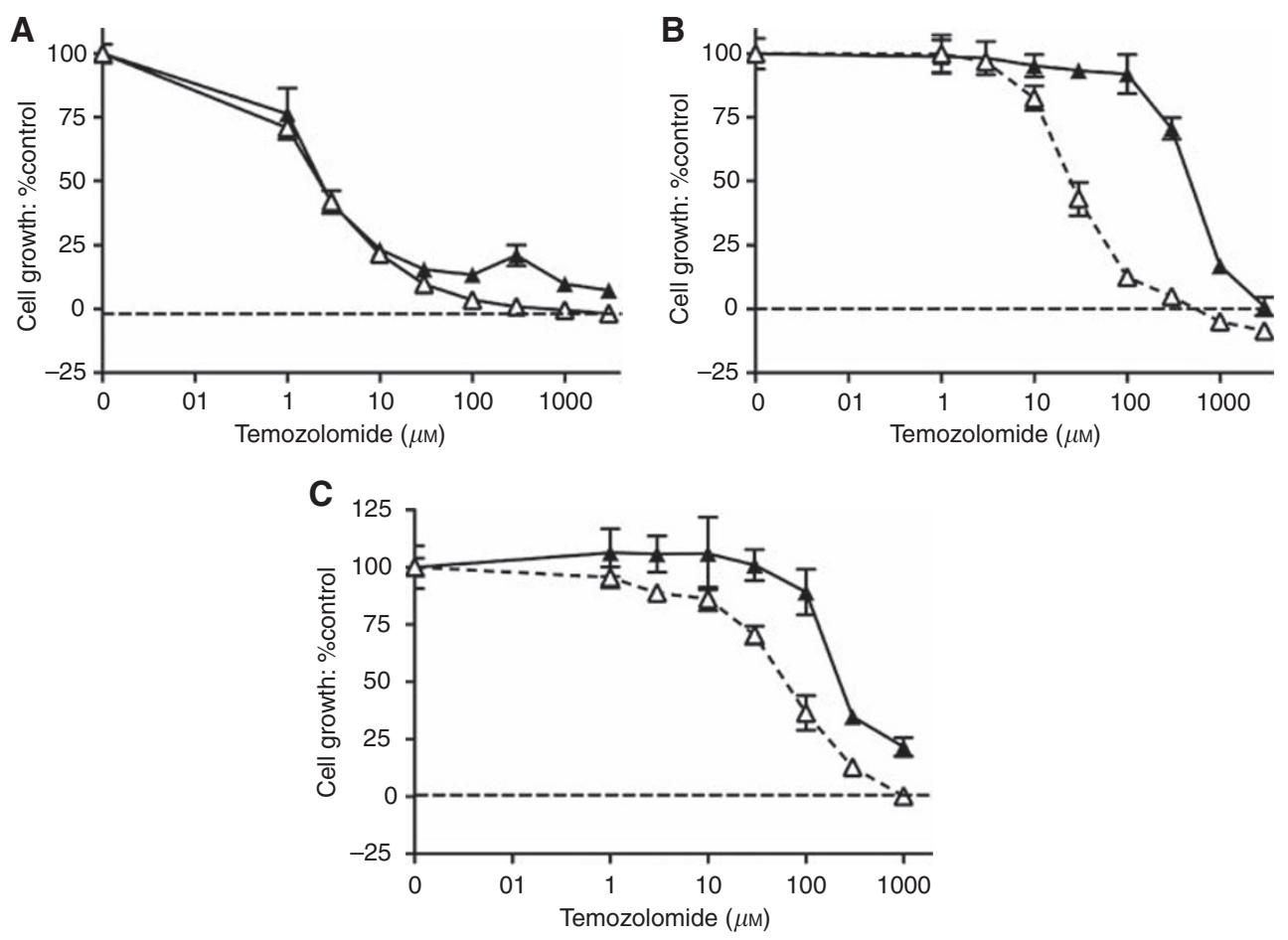

Figure 2 Chemosensitisation to TMZ by AG-014699 in vitro in medulloblastoma cell lines. (A-C) Growth inhibition of D425Med, D283Med and D384Med cells, determined by $X T T$ assay following a 6-day exposure to TMZ either alone (solid triangles) or with $0.4 \mu \mathrm{M}$ AG-0 I 4699 (open triangles). Data are shown normalised to $0.5 \%$ DMSO or $0.4 \mu \mathrm{M}$ AG-0 14699 controls, respectively. A single representative replicate for TMZ $\pm 0.4 \mu \mathrm{M}$ AG-0 I 4699 in D425Med (A), D283Med (B) and D384Med $(\mathbf{C})$ cells ( $\pm 95 \%$ confidence intervals $(\mathrm{Cl})$ ) is shown.

Table I Growth inhibition by temozolomide and sensitisation by AG-0I4699

\begin{tabular}{lccc}
\hline Cell line & $\mathbf{G l}_{\mathbf{5 0}}$ temozolomide $(\boldsymbol{\mu} \mathbf{M})$ & $\mathbf{G l}_{\mathbf{5 0}}$ temozolomide $+\mathbf{A G - 0 1 4 6 9 9}(\boldsymbol{\mu} \mathbf{M})$ & $\mathbf{P F}_{\mathbf{5 0}}$ \\
\hline D425Med & $9.3 \pm 7.5^{\mathrm{a}}$ & $13.3 \pm 3.2$ & $0.7 \pm 0.4$ \\
D283Med & $807 \pm 239$ & $42 \pm 15^{*}$ & $19 \pm 4.7$ \\
D384Med & $220 \pm 42$ & $60 \pm 13 * *$ & $3.8 \pm 1$ \\
\hline
\end{tabular}

Abbreviations: $\mathrm{Gl}_{50}=$ inhibition of growth by $50 \%$; $\mathrm{Pl}_{50}=$ potentiation factor 50 . ${ }^{\mathrm{a}} \mathrm{Data}$ are means and standard deviation of three independent experiments of the type shown in Figure 2. *Significantly different from temozolomide alone $(P=0.005$, Student's two-tailed $t$-test). **Significantly different from temozolomide alone $(P=0.003$, Student's two-tailed $t$-test).

(26.4 and $21.9 \mu \mathrm{moll}^{-1} \min$ on days 1 and 4) and half-life (299 and $254 \mathrm{~min}$ ) were similar to those reported previously (Thomas et al, 2007). The AUCs in the brain (37.0 and $14.7 \mu \mathrm{moll}^{-1} \mathrm{~min}$ on days 1 and 4 ) were comparable to those in the plasma, whereas AUCs in tumour were substantially higher (582.0 and $509.6 \mu \mathrm{moll}^{-1} \mathrm{~min}$ ).

Consistent with the AG-014447 distribution data, PARP activity was suppressed in both brain and tumour tissue following administration of AG-014699. In the brain, PARP activity was reduced by around $75 \%$ for the first $2 \mathrm{~h}$, recovering gradually thereafter, such that it was approximately $40 \%$ reduced at $24 \mathrm{~h}$ (Figure 3Bi). After the fourth daily dose, however, there was less suppression and more rapid recovery such that near-normal activity was detected at $24 \mathrm{~h}$ (Figure $3 \mathrm{Bii}$ ). This presumably reflects the lower AUC of the drug in this tissue after the fourth dose. In contrast, in the tumour, inhibition of PARP activity was slightly delayed, reaching a nadir of around 75\% reduction at $6 \mathrm{~h}$ post-injection, which was similar (barring obvious outlier data) after the first and fourth dose (Figure 3Ci and ii). The modest recovery at $24 \mathrm{~h}$ did appear greater after the fourth dose than the first, however.

\section{Efficacy of temozolomide with AG-014699 in human tumour xenografts}

We examined the effect of AG-014699 on the anti-tumour activity of temozolomide in mice bearing established subcutaneous D425Med, D283Med or D384Med xenografts. Mice were treated daily for 5 days with either vehicle control alone, AG-014699 alone (1 $\mathrm{mg} \mathrm{kg}^{-1}$ i.p.), TMZ alone $\left(68 \mathrm{mg} \mathrm{kg}^{-1}\right.$ p.o.) or the combination of TMZ (68 $\mathrm{mg} \mathrm{kg}^{-1}$ p.o.) + AG-014699 ( $1 \mathrm{mg} \mathrm{kg}^{-1}$ i.p.) data are summarised in Table 2.

At $1 \mathrm{mg} \mathrm{kg}^{-1}$ daily five times, AG-014699 alone did not cause any marked toxicity or affect tumour growth compared with vehicle-only controls. The D425Med cells grew relatively slowly (median time to RTV4=19 days) and, as expected from the in vitro data, were very responsive to temozolomide alone with complete tumour regressions seen in all mice (Figure 4A). These regressions were sustained for the designated experimental period (100 days) in two out of five mice. Co-administration of AG-014699 with temozolomide also resulted in complete tumour regressions in all mice, of which three out of five were sustained throughout the experiment. The MMR-defective D283Med 
A i
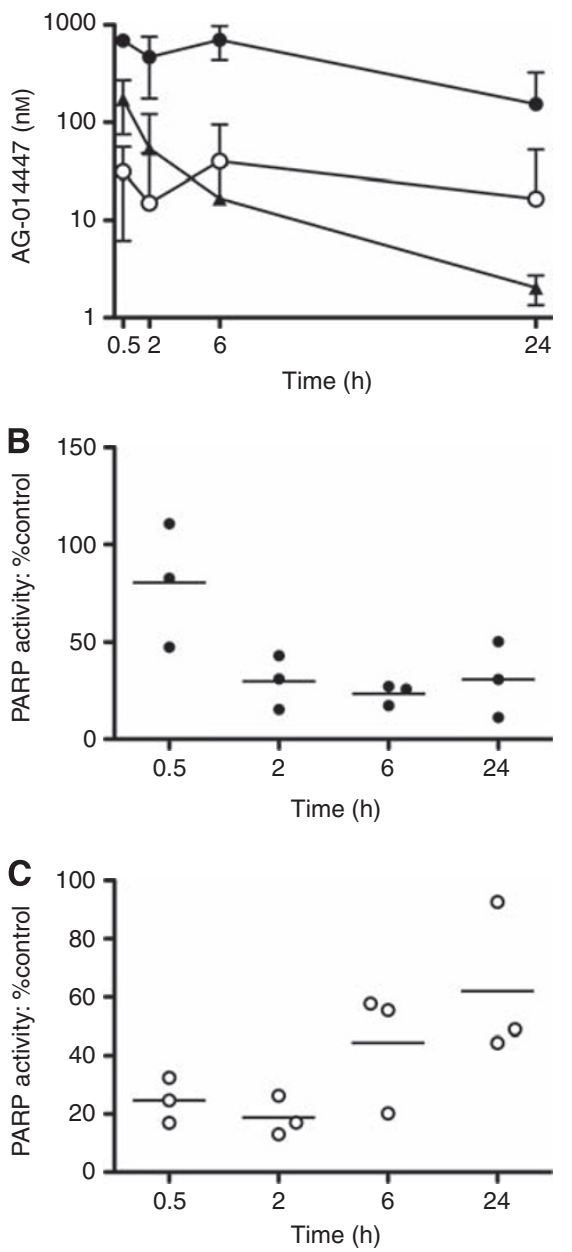

ii
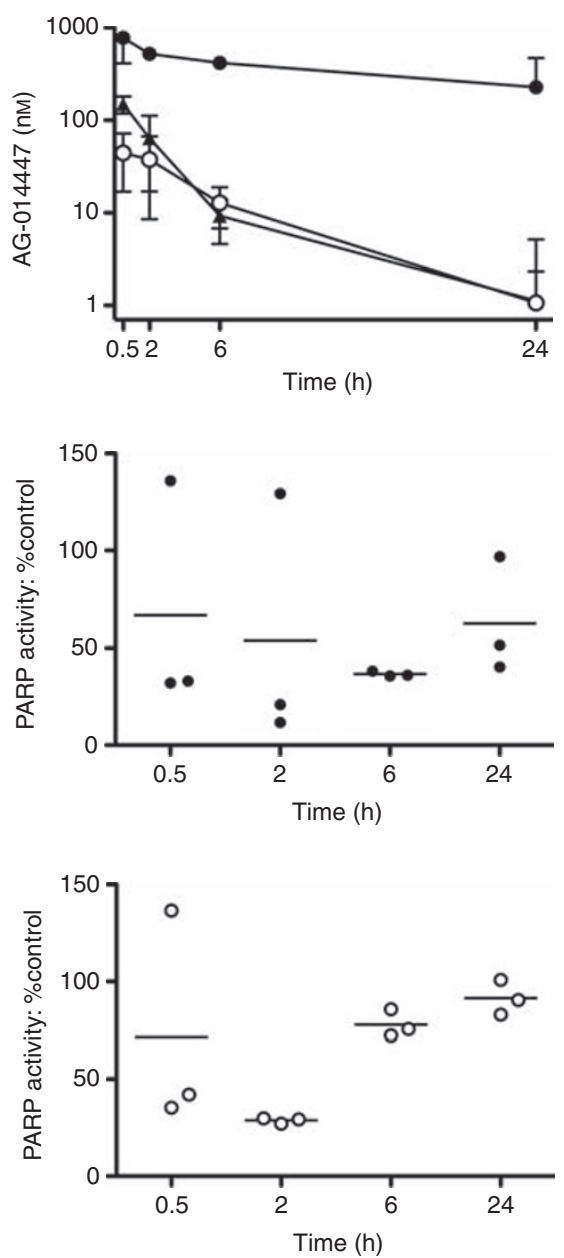

Figure 3 AG-0I4699 pharmacokinetics and PARP-I inhibition in mouse brain and medulloblastoma xenograft. Following a single (i) or the last of four daily doses (ii) of AG-0 4699 (I mg kg-1, i.p.), samples were taken and tissues harvested at the indicated times post-administration: (A) concentration of AG-0I 4447 in plasma (solid triangle), brain (open circle) and D283Med xenograft homogenates (solid circle) from tumour-bearing mice. Corresponding PARP-I activity in D283Med xenograft homogenates $(\mathbf{B})$ and the brain $(\mathbf{C})$ is shown. Concentrations of AG-0I4447 are given as the mean ( $\pm 95 \% \mathrm{Cl}$ ) from three tumour-bearing mice per time point; PARP activity measurements are given as individual values with the horizontal lines indicating the mean value.

xenografts grew very rapidly (median time to RTV4 $=7$ days) and showed very little response to temozolomide alone (TGD of only 2 days) with no regressions observed in any mice (Figure 4B). In contrast to the pronounced in vitro sensitisation, co-administration of AG-014699 only increased this TGD to 2.5 days. The D384Med xenografts, proficient in both MGMT and MMR pathways of DNA repair, grew at an intermediate rate (median time to $\mathrm{RTV} 4=16$ days). Temozolomide alone caused a significant TGD $(P=0.016)$, extending the time to RTV4 to 44.5 days (Figure $4 \mathrm{C}$ ), and the combination with AG-014699 the time to RTV4 was 62 days. Thus, the temozolomideinduced TGD of 28.5 days was extended to 46 days by co-administration of AG-014699, equivalent to a $61 \%$ increase in efficacy; however, this was not quite significant $(P=0.11$ Mann - Whitney test). There was one transient complete response seen in both the temozolomide alone and the temozolomide + AG-014699 groups. Temozolomide alone caused a modest (5 $\pm 4 \%)$, but statistically significant, weight loss relative to control ( $P=0.0006$, unpaired $t$-test). AG-014699 was not toxic per se ( $1 \pm 1 \%$ body weight loss), but caused a modest, but significant, enhancement of temozolomide-induced body weight loss $(10 \pm 6 \%$ weight loss: $P=0.013$, unpaired $t$-test).

\section{DISCUSSION}

In the work described here, we sought to address the need for new therapeutic approaches to improve outcome in medulloblastoma. Temozolomide shows good activity in adult glioblastomas (Mrugala and Chamberlain, 2008) and encouraging data are emerging from Phase I and II studies in paediatric intracranial malignancies, including medulloblastoma (Barone et al, 2006; Baruchel et al, 2006; Nicholson et al, 2007; Wang et al, 2009). We assessed the efficacy of temozolomide alone, and in combination with the PARP inhibitor AG-014699 in medulloblastoma, using three models (D384Med, D425Med and D283Med), which are genetically representative of the primary disease (Langdon et al, 2006). We also investigated pharmacokinetics, pharmacodynamics and toxicity of AG-014699, and show for the first time uptake into CNS and significant and sustained PARP inhibition in brain tissue.

We initially investigated in our models the status of molecular pathways implicated in the modulation of temozolomide sensitivity (i.e. DNA MMR and MGMT; Middlemas et al, 2000). Our cell lines modelled closely the diversity observed in primary medulloblastomas; D384Med cells were proficient for all proteins tested, indicating they reflect the vast majority of primary 
Table 2 Toxicity and efficacy of TMZ and AG-0I4699 in medulloblastoma xenografts

\begin{tabular}{|c|c|c|c|c|c|}
\hline Xenograft & Treatment & $\begin{array}{c}\text { Median nadir body } \\
\text { weight (\% starting weight) }\end{array}$ & $\begin{array}{l}\text { Median time } \\
\text { to RTV4 (days) }\end{array}$ & $\begin{array}{l}\text { Tumour growth } \\
\text { delay (days) (\% enhancement) }\end{array}$ & $\begin{array}{l}\text { Complete } \\
\text { regressions }\end{array}$ \\
\hline D425Med & $\begin{array}{l}\text { Control } \\
\text { AG-0I4699 } \\
\text { TMZ } \\
\text { Combination }\end{array}$ & $\begin{array}{l}98 \\
98 \\
96 \\
95\end{array}$ & $\begin{aligned} & 19 \\
& 15.5 \\
> & 100 \\
> & 100\end{aligned}$ & $\begin{array}{c}>81 \\
>81(N / A)\end{array}$ & $\begin{array}{l}0 / 5 \\
0 / 5 \\
2 / 5 \\
3 / 5\end{array}$ \\
\hline D283Med & $\begin{array}{l}\text { Control } \\
\text { AG-0I4699 } \\
\text { TMZ } \\
\text { Combination }\end{array}$ & $\begin{array}{r}98 \\
100 \\
94 \\
91\end{array}$ & $\begin{array}{l}7 \\
8 \\
9 \\
9.5\end{array}$ & $\begin{array}{c}1 \\
2 \\
2.5(25 \%)\end{array}$ & $\begin{array}{l}0 / 5 \\
0 / 5 \\
0 / 5 \\
0 / 5\end{array}$ \\
\hline D384Med & $\begin{array}{l}\text { Control } \\
\text { AG-0I4699 } \\
\text { TMZ } \\
\text { Combination }\end{array}$ & $\begin{array}{r}100 \\
96 \\
97 \\
90\end{array}$ & $\begin{array}{l}16 \\
20 \\
44.5 \\
62\end{array}$ & $\begin{array}{c}4 \\
28.5 \\
46(61 \%)\end{array}$ & $\begin{array}{l}0 / 5 \\
0 / 5 \\
1 / 5 \\
1 / 5\end{array}$ \\
\hline
\end{tabular}

Abbreviations: N/A = not applicable; RTV = relative tumour volume; $\mathrm{TMZ}=$ temozolomide; $\mathrm{Pl}_{50}=$ potentiation factor ${ }_{50}$.
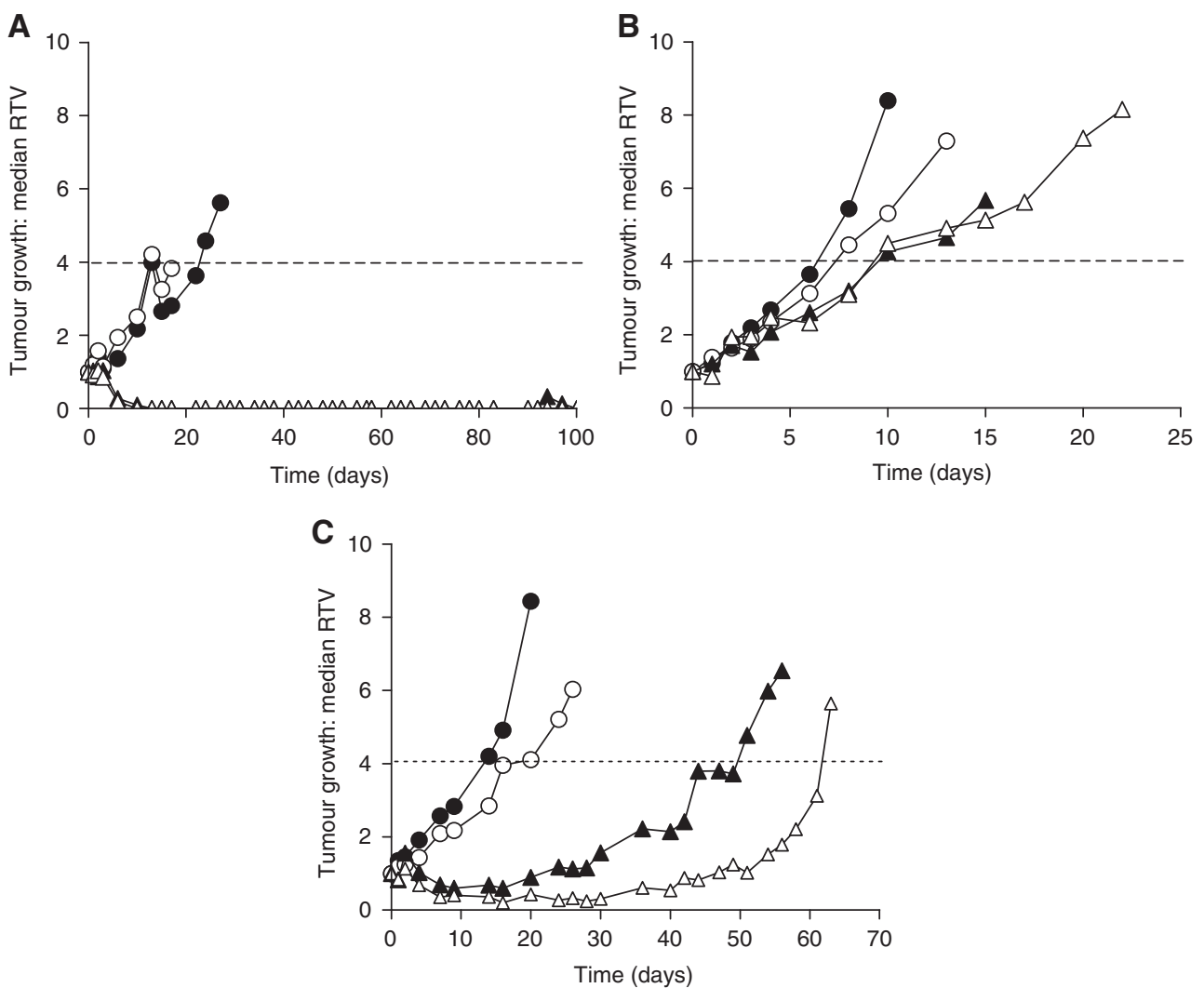

Figure 4 Enhancement of TMZ efficacy by AG-014699 in in vivo models of medulloblastoma. Growth of D425Med (A), D283Med (B) or D384Med (C) tumour xenografts over a 100 -day period, following daily treatment for 5 days with vehicle control alone (solid circles), AG-0I4699 alone (I mg kg ${ }^{-1}$, open circles), TMZ alone (68 $\mathrm{mg} \mathrm{kg}^{-1}$, solid triangles) or TMZ $\left(68 \mathrm{mg} \mathrm{kg} \mathrm{g}^{-1}\right)+\mathrm{AG}-0 \mathrm{I} 4699\left(\mathrm{I} \mathrm{mg} \mathrm{kg}^{-1}\right)$ (open triangles). Dashed horizontal line corresponds to RTV4. Data are median of five mice per group until first humane killing owing to tumour burden.

medulloblastomas, in which MMR deficits (observed in $\sim 10 \%$ of cases; Viana-Pereira et al, 2009) and MGMT hypermethylation ( $\sim 25 \%$ of cases; Lindsey et al, 2005) are relatively uncommon. Data for our other cell lines were consistent with their relevance as models of primary cases associated with MMR (D283Med) and MGMT (D425Med) deficiency. In subsequent efficacy testing, the MGMT-deficient D425Med cells were very sensitive to temozolomide both in cell cultures and as xenografts, being nearly 25 times more sensitive than the MGMT-proficient D384Med cells in culture, and showing complete tumour regressions in response to temozolomide alone in in vivo experiments. The sensitivity of
D425Med to temozolomide alone may limit the usefulness of this cell line in assessing sensitisation by inhibition of PARP.

Previous studies in paediatric xenografts have also concluded that MGMT status is the major determinant of sensitivity to temozolomide, but that MMR defects also confer resistance (Middlemas et al, 2000). This was clearly illustrated in our panel by MMR-defective D283Med cells, which were nearly four times less sensitive to temozolomide than D384Med cells and xenografts derived from these cells showed barely any response to temozolomide therapy. In cell culture experiments, AG-014699, at a concentration that inhibited PARP by $>95 \%$, did not enhance 
temozolomide sensitivity in the MGMT-defective cells, but caused a striking 20-fold enhancement in the MMR-defective D283Med cells. These observations are in line with our previous observations in adult human cancer cell lines (Calabrese et al, 2004; Curtin et al, 2004; Thomas et al, 2007). These data reflect the molecular pathology of the cells and hence the relative contribution that $\mathrm{O}^{6}$-methylguanine and $\mathrm{N}^{7}$-methylguanine and $\mathrm{N}^{3}$-methyladenine (that are repaired by PARP-dependent processes) make to the overall cytotoxicity of temozolomide in the individual cell lines.

In the in vivo chemosensitisation studies, co-administration of AG-014699 caused an approximately $60 \%$ increase in temozolomide-induced TGD in the DNA repair protein-competent D384Med xenografts but, owing to the small sample number, the effect was not significant $(P=0.11)$. In comparison, the D425Med tumours grew relatively slowly and responded well to temozolomide alone, with all mice showing complete tumour regressions, two of which were sustained until the termination of the experiment at 100 days. Xenografts from MGMT-deficient SW620 cells show similar sensitivity to temozolomide alone, but are sensitised further by AG14361 and AG-014699 (Calabrese et al, 2004; Thomas et al, 2007), most probably because of the vasoactivity of these PARP inhibitors (Ali et al, 2009). We had therefore expected to see potentiation of temozolomide antitumour activity in D425Med tumours by AG-014699. The number of complete regressions persisting to the end of the experiment was three out of five in the temozolomide + AG-014699 group, compared with two out of five in the temozolomide alone. On the basis of the small sample size, this cannot be considered significant, but is nevertheless encouraging. The lack of sensitisation by AG-014699 of the anti-tumour effect of temozolomide in MMR-defective D283Med xenografts was surprising, given the degree of potentiation seen in vitro. The lack of effect of AG-014699 in the D283Med xenografts was not due to PK/PD limitations, as accumulation of AG-0144447 and substantial PARP inhibition was shown in the tumours. MMR defects are observed in only a minority of medulloblastomas and the lack of synergy in this model does not undermine the rationale for combining PARP inhibitors with temozolomide. Thus, in summary, we propose that the D384Med model most faithfully reflects the clinical situation in the majority of medulloblastoma cases. The indication of chemosensitisation observed in this model is therefore encouraging and warrants further investigation in a wider panel of MMR- and MGMT-competent medulloblastoma models.

We have not previously determined the CNS penetration of AG-014447, the free drug of which AG-014699 is the phosphate salt, nor its inhibition of PARP activity in the brain. We saw clear evidence of AG-014447 penetration into brain tissue, and accompanying evidence of PARP inhibition, in mice with an intact BBB. PARP activity in the brain was higher than expected for a non-dividing tissue, with the activity being in the range 88-106 pmol PAR per mg protein per min. Although significantly lower than that detected in the associated tumour xenografts (1402-3236 pmol PAR per mg protein per min), it was comparable with the activity detected in normal mouse liver and kidney (98-106 pmol PAR per $\mathrm{mg}$ protein per $\min$ in the livers, 69-76 pmol PAR per $\mathrm{mg}$ protein per $\min$ in the kidneys, unpublished observations). Although concentrations of AG-014447 achieved in the brain (20-60 nM) were lower than were used for in vitro chemosensitisation, the inhibition of PARP activity over the 24 -h period was $50-80 \%$. This level of inhibition is in general agreement with the $80 \%$ inhibition of activity seen in permeabilised cells exposed to $100 \mathrm{nM}$ AG-014699, and is sufficient to cause in vivo chemosensitisation in models of both adult and paediatric malignancies (Calabrese et al, 2004; Daniel et al, 2009). Importantly, the peak plasma level in mice treated with AG-014699 at $1 \mathrm{mg} \mathrm{kg}^{-1}$ was $42-68 \mathrm{ng} \mathrm{ml}^{-1}$, which is approximately $1 / 10$ th the concentration in patients treated with the recommended Phase II dose of $12 \mathrm{mg} \mathrm{m}^{-2}\left(473-675 \mathrm{ng} \mathrm{ml}^{-1}\right)$. Therefore, higher drug levels and greater PARP inhibition should be achievable in the brains of patients treated with a safe dose of AG-014699. The observed accumulation of AG-014447 in xenografted medulloblastomas, which is consistent with our data for other tumour types coupled with a potentially compromised blood-brain tumour barrier suggests that drug accumulation in the tumours may be even higher. Further investigations in orthotopic or spontaneous transgenic models of medulloblastoma could provide useful insights in this regard, although the limitations of these models as representative of primary tumours and an intact BBB must also be taken into account.

Several PARP inhibitors have been shown to penetrate CNS tissue and to have a pharmacological effect, either in terms of an enhancement of the anti-tumour activity of temozolomide against intra-cranial tumours or reduction in focal ischaemia in a stroke model (Tentori et al, 2003; Hattori et al, 2004; Cheng et al, 2005; Donawho et al, 2007). Indeed, one of the indications of PARP inhibitors is in the reduction of brain tissue damage following stroke (Jagtap and Szabo, 2005). However, to the best of our knowledge, this is the first time that inhibition of PARP activity in the brains of mice treated with a PARP inhibitor has been shown.

In summary, the data we present here shows encouraging enhancement of temozolomide activity in pre-clinical cell line models of medulloblastoma, representative of the spectrum of sensitivity to single-agent temozolomide. Furthermore, following a non-toxic dose of AG-014699, good CNS penetration and correspondingly substantial inhibition of PARP activity in nervous tissue was observed in association with AG-014699 plasma levels $1 / 10$ th of those detected in patients treated with the recommended Phase II dose, and without significant toxicity. Further validation of these observations in a wider range of cell lines and in orthotopic models are required before a clinical evaluation of AG-014699 in combination with temozolomide for intra-cranial malignancies would be indicated.

\section{ACKNOWLEDGEMENTS}

We are grateful to Cancer Research UK for supporting this study, Pfizer for the provision of AG-014699 and Professor Alex Burkle, University of Konstanz for the $10 \mathrm{H}$ antibody. This work was supported by Cancer Research UK Grant C8464/A5414 (S Clifford, $\mathrm{N}$ Curtin, D Tweddle and A Boddy). D Tweddle is a recipient of a UK Department of Health Clinician Scientist Fellowship.

\section{Conflict of interest}

$\mathrm{ZH}$ is an employee of, and NJC and ERP have received financial support from, Pfizer Inc.

\section{REFERENCES}

Ali M, Telfer BA, McCrudden C, O'Rourke M, Thomas HD, Kamjoo M, Kyle S, Robson T, Shaw C, Hirst DG, Curtin NJ, Williams KJ (2009) Vasoactivity ofAG014699, a clinically active small molecule inhibitor of poly(ADP-ribose) polymerase: a contributory factor to chemopotentiation in vivo? Clin Cancer Res 15: 6106-6112

Barone G, Maurizi P, Tamburrinin G, Riccardi R (2006) Role of temozolomide in paediatric brain tumours. Childs Nerv Syst 22: 652-661
Baruchel S, Diezia M, Hargrave D, Stempak D, Gammon J, Moghrabi A, Coppes MJ, Fernandez CV, Bouffet E (2006) Safety and pharmacokinetics of temozolomide using a dose-escalation, metronomic schedule in recurrent paediatric brain tumours. Eur J Cancer 42: 2335-2342

Broniscer A, Gururangan S, MacDonald TJ, Goldman S, Packer RJ, Stewart CF, Wallace D, Danks MK, Friedman HS, Poussaint TY, Kun LE, Boyett JM, Gajjar A, for the Pediatric Brain Tumor Consortium. 
(2007) Phase I trial of single-dosetemozolomide and continuous administration of o6-benzylguanine in children with brain tumors: a pediatric brain tumor consortium report. Clin Cancer Res 13: 6712-6718

Calabrese CR, Almassy R, Barton S, Batey MA, Calvert AH, Canan-Koch S, Durkacz BW, Hostomsky Z, Kumpf RA, Kyle S, Li J, Maegley K, Newell DR, North M, Notarianni E, Stratford IJ, Skalitzky D, Thomas HD, Wang L-Z, Webber SE, Williams KJ, Curtin NJ (2004) Preclinical evaluation of a novel poly(ADP-ribose) polymerase-1 (PARP-1) inhibitor, AG14361, with significant anticancer chemo- and radio-sensitization activity. J Natl Cancer Inst 96: 56-67

Cheng CL, Johnson SP, Keir ST, Quinn JA, Ali-Osman F, Szabo C, Li H, Salzman AL, Dolan ME, Modrich P, Bigner DD, Friedman HS (2005) Poly(ADP-ribose) polymerase-1 inhibition reverses temozolomide resistance in a DNA mismatch repair-deficient malignant glioma xenograft. Mol Cancer Ther 4: 1364-1368

Curtin NJ (2007) Therapeutic potential of drugs to modulate DNA repair in cancer. Expert Opin Therap Targets 11: 783-799

Curtin NJ, Wang L-Z, Yiakouvaki A, Kyle S, Arris CE, Canan-Koch S, Webber SE, Durkacz BW, Calvert AH, Newell DR, Hostomsky Z (2004) Novel PARP-1 inhibitor, AG14361, restores sensitivity to temozolomide in mismatch repair deficient cells. Clin Cancer Res 10: 881-889

Daniel RA, Rozanska AL, Thomas HD, Mulligan EA, Drew Y, Castelbuono DJ, Hostomsky Z, Plummer ER, Boddy AV, Tweddle DA, Curtin NJ, Clifford SC (2009) Inhibition of poly(ADP-ribose) polymerase-1 enhances temozolomide and topotecan activity against childhood neuroblastoma. Clin Cancer Res 15: $1241-1249$

Deeken JF, Loscher W (2007) The blood-brain barrier and cancer: transporters, treatment and Trojan horses. Clin Can Res 13: $1663-1674$

Donawho CK, Luo Y, Luo Y, Penning TD, Bauch JL, Bouska JJ, BontchevaDiaz VD, Cox BF, DeWeese TL, Dillehay LE, Ferguson DC, GhoreishiHaack NS, Grimm DR, Guan R, Han EK, Holley-Shanks RR, Hristov B, Idler KB, Jarvis K, Johnson EF, Kleinberg LR, Klinghofer V, Lasko LM, Liu X, Marsh KC, McGonigal TP, Meulbroek JA, Olson AM, Palma JP, Rodriguez LE, Shi Y, Stavropoulos JA, Tsurutani AC, Zhu GD, Rosenberg SH, Giranda VL, Frost DJ (2007) ABT-888, an orally active poly(ADPribose) polymerase inhibitor that potentiates DNA-damaging agents in pre-clinical tumour models. Clin Can Res 13: 2728-2737

Fong PC, Bass DS, Yap TA, Carden CP, Mergui-Roelvink M, Gourley C, De Greve J, Lubinski J, Shanley S, Messiou C, A'Hern R, Tutt A, Ashworth A, Stone J, Carmichael J, Schellens JH, de Bono JS, Kaye SB (2009) Inhibition of poly(ADP-ribose) polymerase in tumours from BRCA mutation carriers. $N$ Engl J Med 361: $123-134$

Friedman HS, Dolan ME, Pegg AE, Marcelli S, Keir S, Catino JJ, Bigner DD, Schold Jr SC (1995) Activity of temozolomide in the treatment of central nervous system tumor xenografts. Cancer Res 55: 2853-2857

Hattori K, Kido Y, Yamamoto H, Ishida J, Iwashita A, Mihara K (2004) Rational approaches to discovery of orally active and brain-penetrable quinazoline inhibitors of poly(ADP-ribose) polymerase. J Med Chem 47: $4151-4154$

Hegi ME, Diserens AC, Gorlia T, Hamou MF, de Tribolet N, Weller M, Kros JM, Hainfellner JA, Mason W, Mariani L, Bromberg JE, Hau P, Mirimanoff RO, Cairncross JG, Janzer RC, Stupp R (2005) MGMT gene silencing and benefit from temozolomide in glioblastoma. N Engl J Med 352: $997-1003$

Jagtap P, Szabo C (2005) Poly(ADP-ribose) polymerase and the therapeutic potential of its inhibitors. Nat Rev Drug Disc 4: 421-440

Langdon JA, Lamont JM, Scott DK, Dyer S, Prebble E, Bown N, Grundy RG, Ellison DW, Clifford SC (2006) Combined genome-wide allelotyping and copy number analysis identify frequent genetic losses without copy number reduction in medulloblastoma. Genes Chromosomes Cancer 45: 47-60

Lindsey JC, Anderton JA, Lusher ME, Clifford SC (2005) Epigenetic events in medulloblastoma development. Neurosurg Focus 19: E10
Macdonald DR (2001) Temozolomide for recurrent high-grade glioma. Semin Oncol 28: 3-12

Middlemas DS, Stewart CF, Kirstein MN, Poquette C, Friedman HS, Houghton PJ, Brent TP (2000) Biochemical correlates of temozolomide sensitivity in pediatric solid tumor xenograft models. Clin Cancer Res 6: $998-1007$

Mrugala MM, Chamberlain MC (2008) Mechanisms of disease: temozolomide and glioblastoma - look to the future. Nat Clin Pract Oncol 5: $476-486$

Nicholson HS, Kretschmar CS, Krailo M, Bernstein M, Kadota R, Fort D, Friedman H, Harris MB, Tedeschi-Blok N, Mazewski C, Sato J, Reaman GH (2007) Phase 2 study of temozolomide in children and adolescents with recurrent central nervous system tumors. Cancer 110: $1542-1550$

Pizer B, Clifford S (2008) Medulloblastoma: new insights into biology and treatment. Arch Dis Child Educ Pract Ed 93: 137-144

Pizer B, Clifford SC (2009) The potential impact of tumour biology on improved clinical practice for medulloblastoma: progress towards biologically driven clinical trials. Br J Neurosurg 23: 364-375

Plummer ER, Middleton MR, Jones C, Olsen A, Hickson I, McHugh P, Margison G, McGown G, Thorncroft M, Watson AJ, Boddy AV, Calvert AH, Harris AL, Newell DR, Curtin NJ (2005) Temozolomide pharmacodynamics in patients with metastatic melanoma: DNA damage and activity of repair enzymes ATase and PARP-1. Clin Cancer Res 11: $3402-3409$

Plummer R, Jones C, Middleton M, Wilson R, Evans J, Olsen A, Curtin N, Boddy A, McHugh P, Newell D, Harris A, Johnson P, Steinfeldt H, Dewji R, Wang D, Robson L, Calvert H (2008) Phase I sStudy of the poly(ADP-Ribose) polymerase inhibitor, AG-014699, in combination with temozolomide in patients with advanced solid tumors. Clin Cancer Res 14: 7917-7923

Plummer R, Lorigan P, Evans J, Steven N, Middleton M, Wilson R, Snow K, Dewji R, Calvert H (2006) First and final report of a phase II study of the poly(ADP-ribose) polymerase (PARP) inhibitor, AG-014699, in combination with temozolomide (TMZ) in patients with metastatic malignant melanoma (MM). J Clin Oncol 2006 ASCO Annual Meeting Proceedings 2006. Part I 24(18S): 8013

Rosso L, Brock CS, Gallo JM, Saleem A, Price PM, Turkheimer FE, Aboagye EO (2009) A new model for prediction of drug distribution in tumor and normal tissues: pharmacokinetics of temozolomide in glioma patients. Cancer Res 69: 120-127

Tentori L, Leonetti C, Scarsella M, Muzi A, Mazzon E, Vergati M, Forini O, Lapidus R, Xu W, Dorio AS, Zhang J, Cuzzocrea S, Graziani G (2003) Systemic administration of GPI 15427, a novel poly(ADP-ribose) polymerase-1 inhibitor, increases the antitumor activity of temozolomide against intracranial melanoma, glioma, lymphoma. Clin Cancer Res 9: $5370-5379$

Thomas HD, Calabrese CR, Batey MA, Canan S, Hostomsky Z, Kyle S, Maegley KA, Newell DR, Skalitzky D, Wang L-Z, Webber SE, Curtin NJ (2007) Preclinical selection of a novel poly(ADP-ribose) polymerase (PARP) inhibitor for clinical trial. Mol Cancer Ther 6: 945-956

van den Bent MJ, Taphoorn MJ, Brandes AA, Menten J, Stupp R, Frenay M, Chinot O, Kros JM, van der Rijt CC, Vecht ChJ, Allgeier A, Gorlia T (2003) Phase II study of first-line chemotherapy with temozolomide in recurrent oligodendroglial tumors: the European Organization for Research and Treatment of Cancer Brain Tumor Group Study 26971. J Clin Oncol 21: 2525-2528

Viana-Pereira M, Almeida I, Sousa S, Mahler-Araújo B, Seruca R, Pimentel J, Reis RM (2009) Analysis of microsatellite instability in medulloblastoma. Neuro Oncol 11: 458-467

Wang CH, Hsu TR, Wong TT, Chang KP (2009) Efficacy of temozolomide for recurrent embryonal brain tumours in children. Childs Nerv Syst 25 $535-541$ 